\title{
Changes in the effects of heat on mortality among the elderly from 1998-2010: results from a multicenter time series study in Italy
}

Patrizia Schifano ${ }^{*}$, Michela Leone, Manuela De Sario, Francesca de’Donato, Anna Maria Bargagli, Daniela D'lppoliti, Claudia Marino and Paola Michelozzi

\begin{abstract}
Background: This multicenter study is aimed at estimating changes in the effect of high temperatures on elderly mortality before and after the 2003 heat waves and following the introduction of heat prevention activities.

Methods: A total of sixteen cities were included in the study. City-specific relationships between maximum apparent temperature (MAT) and elderly daily mortality before (1998-2002) and after (2006-2010) intervention were modelled through non-linear distributed lag models and estimates were combined using a random effect meta-analysis. We estimated the percentage change in daily mortality for $3^{\circ} \mathrm{C}$ variations in MAT above the $25^{\text {th }}$ percentile of the June city-specific 1998-2002 distribution.

A time-varying analysis was carried out to describe intra-seasonal variations in the two periods.

Results: We observed a reduction in high temperatures' effect post intervention; the greatest reduction was for increases in temperature from $9^{\circ} \mathrm{C}$ to $12^{\circ} \mathrm{C}$ above the $25^{\text {th }}$ percentile, with a decrease from $+36.7 \%$ to $+13.3 \%$. A weak effect was observed for temperatures up to $3^{\circ} \mathrm{C}$ above the $25^{\text {th }}$ percentile only after. Changes were month-specific with a reduction in August and an increase in May, June and September in 2006-2010.

Conclusions: A change in the temperature-mortality relationship was observed, attributable to variations in temperature distributions during summer and to the introduction of adaptation measures. The reduction in the effect of high temperature suggests that prevention programs can mitigate the impact. An effect of lower temperature remains, indicating a relevant impact of temperature at the beginning of summer when the population has not yet adapted and intervention activities are not fully operational.
\end{abstract}

Keywords: Prevention plan, Heat, Non linear model, Mortality, Elderly

\section{Background}

Reducing the effects of heat on health is one of the priorities identified by the WHO [1]. Changes in the effects of heat on human health depend not only on changes in levels of heat exposure, but also on variations in the characteristics of populations which confer a greater susceptibility and in the adaptive capacity due to individual and community efforts [2]. Studies mainly from the US have documented a decline in heat-related mortality in the last decades [3-6], which has been attributed to technological improvements and to changes in socio-demographic characteristics of the

\footnotetext{
* Correspondence: p.schifano@deplazio.it

Department of Epidemiology, Lazio Regional Health Service, Via di Santa Costanza, Roma 53, 00198, Italy
}

population, or to adaptive measures. In Europe evidence of time variations in heat-related mortality is limited and the few studies have mainly focused on comparing the impact of the 2003 heat waves with that of heat waves in the following years [7-10]. In several European countries after 2003, warning systems and a number of specific public health interventions have been widely introduced, however the actual level of implementation of different response measures was heterogeneous $[11,12]$, and evidence of the effectiveness of specific preventive activities is still lacking $[11,13,14]$.

Evaluating the effectiveness of heat-health action plans is extremely difficult for several reasons. First of all, programs within the same country are very heterogeneous 
and the same program can vary from year to year. Furthermore, it is difficult to plan a study design able to take into account all the potential confounders and effect modifiers of a plan's effectiveness. Randomized trials (RCT) are very difficult in this context for ethical and organizational reasons [15], and, observational studies have important limits due to the identification of a proper control population and to the type of intervention to be evaluated. However, it is necessary from both an epidemiological and a public health point of view to give a description of changes occurring in the heat-mortality relationship over time to allow public health decision makers to make evidence-based choices, to better allocate available resources and to address future research to the most urgent problems.

In Italy, a national program for the prevention of the effects of heat on subjects aged 65 years and older has been operational since 2004, supported by the Department of Civil Protection and the Ministry of Health [12]. To date, it includes 34 major cities, which differ in climate and socio-demographic characteristics, and covers $21 \%$ of Italian residents aged 65 years and over.

The main components of the program are city-specific heat health watch warning systems (HHWWS), national prevention guidelines on which local prevention measures are developed, the identification of susceptible subgroups on whom prevention activities are targeted and the definition of a rapid mortality surveillance system. Although there are differences between prevention plans at the local level the key component is the active surveillance of high risk patients by general pratictioners (GPs). When level 2 and level 3 warnings are issued by the HHWWS, GPs monitor their patients through telephone calls and home visits, and provide specific interventions such as modulation of pharmacological treatment, requesting for home-based treatment and giving special attention to high risk patients recently discharged from hospitals. Details on the Italian heat plan are reported elsewhere [12].

The present multicenter study evaluates temporal changes in the impact of summer temperatures on mortality among those older than 65 years, before and after the introduction of the national heat health prevention program in Italy.

\section{Materials and Methods \\ Data}

The study includes data on residents of 16 of the 34 Italian cities included in the National Prevention Program. We selected cities that have had an active HHWWS and local prevention plan since summer 2004 and have complete temperature and mortality time series for the whole study period. The study was restricted to subjects over 65 years of age as prevention programs are targeted to the elderly.

\section{Study period}

The study period includes 1998 to 2002, as the period preceding the introduction of the heat prevention program (pre-intervention), and from 2006 to 2010 as the period following their implementation (post-intervention). We excluded 2003 because of the exceptional meteorological conditions and the related mortality burden observed in many Italian cities [16,17], and years 2004 and 2005 because prevention programs were not fully operational. All analyses were restricted to the warm season defined as the period between May 15th and September 15th.

\section{Outcome measure}

The study outcome is residents' daily mortality from any natural cause that occurred in the selected cities (International Classification of Disease, ICD-9 1-799); data were extracted from local mortality registries and the rapid mortality surveillance system [12].

\section{Exposure measure}

Exposure was measured by daily maximum apparent temperature (MAT) defined as the maximum value between 1200UTC and 1800UTC. Apparent temperature is a discomfort index based on air and dew point temperature $[18,19]$.

Meteorological data refer to the airport station located closest to the city centre and were obtained from the Meteorological Service of the Italian Air Force.

\section{Statistical Analysis}

The city-specific MAT mortality relationship was explored using a Generalized Additive Model (GAM) model and the overall relationship was discerned through a multivariate meta-analysis.

The analysis was developed in two steps. First a common model was applied to each city to obtain cityspecific estimates, and then estimates were combined using a random effect meta-analysis.

It is well known that the strength of the association between temperature and mortality varies according to temperature levels, assuming approximately a Jshaped relationship along the temperature axis. We adopted a non-linear approach to accurately model the temperature-mortality association along the whole range of summer temperatures, providing specific estimates for each temperature value. We used a nonlinear distributed lag model (DLNM) with a Poisson link function, to overcome linearity and simultaneously taking into account the delayed effect of exposure [20].

The mortality-temperature relationship was modelled using a cubic natural spline with six degrees of freedom (df), while the temporal structure was modelled constraining the curve to follow a cubic natural spline with five degrees of freedom. A lag window of up to seven 
days was selected because it has been suggested that it accurately describes the delayed effect of exposure [21]. A preliminary analysis on data from 1998-2002 was carried out using a constrained lag model to define the significant lag structure in each city.

To compare city-specific effects, an exposure indicator was defined based on the difference between daily MAT and a city-specific reference point, corresponding to thermal comfort. The city-specific reference point was defined as the 25th percentile of the MAT summer distribution in the period 1998-2002. We give results for three-degree step increases in MAT above the reference point.

We adjusted for seasonality and long time-trends using indicator variables for days of the week, holiday and month and linear quadratic terms of time, respectively.

In the second step, for each of the temperature intervals previously described, a pooled estimate from all cities was computed with a random effect meta-analysis based on restricted maximum likelihood [22].

Furthermore, in order to understand changes in seasonality of extreme temperature over the study period, a multivariate meta-analytic time-varying analysis was carried out [23]. We estimated the effect of $1^{\circ} \mathrm{C}$ increases in MAT over the $25^{\text {th }}$ city-specific percentile considering a common 0-3 lag for all cities. We assumed that the effect of the exposure follows a sine and cosine function, according to Baccini et al. [24].

A sensitivity analysis was carried out excluding some cities from the meta-analysis. In particular, small cities that might produce an unreliable overall estimate were excluded, as were those with a temperature/mortality trend that differed greatly from the others, because they might increase heterogeneity.

The study did not include human subjects.

\section{Results \\ Data Set}

We included 16 cities in the study that fulfilled the required criteria (Table 1). The number of inhabitants ranges from about 50,000 in Campobasso and Civitavecchia to over 2,5 million in Rome; the percentage of the population over 65 years varies roughly between 14\% in Latina and Palermo to $26 \%$ in Trieste, Bologna, Genova and Trieste. The daily mean number of deaths in $65+$ year olds in the analysed period ranges from less than 1 in Campobasso and Civitavecchia to 45 in Rome (Table 1).

\section{Temperatures Variations}

The 25th percentile value of the MAT distribution pre intervention varied between $24^{\circ} \mathrm{C}$ and $27^{\circ} \mathrm{C}$ with the exception of the city of Campobasso, with a value of $20^{\circ} \mathrm{C}$, and Turin, with a value of $22^{\circ} \mathrm{C}$. The city-specific lag value ranged from 1 to 6 days (Table 1). No important differences in the two periods have been observed. Monthly differences in the $75^{\text {th }}$ percentile of city-specific MAT distribution in the two periods are reported in Figure 1.

The figure shows a shift towards higher values in most cities, with a greater increase during the months of May (with the only exception of the city of Milan and Genoa), July (with the exception of Bari) and September (with the exception of Milan and Genova). MAT percentiles values for the month of June are quite similar for the two periods, while in August values are lower post intervention in all cities except for Brescia, Civitavecchia, Latina and Palermo.

\section{City-specific estimates}

We observed a weaker relationship between heat and mortality in almost all cities post-intervention than in the pre-intervention period (Figure 2), furthermore, a decrease in extremely high temperature values post intervention was observed. Only in Bari and, to a lesser extent in Genoa, did the effect of high temperatures seem to be stronger. No differences could be detected in Florence and Bologna. In some cases the temperaturemortality relationship became almost linear (Trieste, Civitavecchia, Verona, Campobasso, Latina and Viterbo).

During the post-intervention period the lag period shortened in most cities (results not shown).

\section{Overall results}

In Figure 3 the meta-analytic curves of the two periods are reported. The before-after trend more commonly detected in the city-specific curves is shown: a very slight increase in the effect of lower temperatures and a clear reduction of the effect of high temperatures on mortality in the post-intervention period. Also it shows how the upper limit of observed temperatures was lower in the 2006-2010 period.

Dividing the temperature range into three-degree intervals, for each study period we obtained five temperature intervals and five estimates of the exposure-mortality relationship in terms of percent change in mortality risk. City-specific estimates are reported in the Web appendix (Additional file 1:). The test of heterogeneity resulted significant for three of them, specifically between $6^{\circ} \mathrm{C}$ and $12^{\circ} \mathrm{C}$ over the reference pre intervention and between $3^{\circ} \mathrm{C}$ and $6^{\circ} \mathrm{C}$ over the reference post intervention (data not shown).

Table 2 reports the overall estimates of the exposuremortality relationship in terms of percent change in mortality risk per $3^{\circ} \mathrm{C}$ of temperature increase starting from the city- specific reference value. A non-significant increase in mortality was observed up to six degrees above the reference value before the intervention and a 
Table 1 Population size, daily 65+ mortality, maximum apparent temperature (MAT) and lag by city

\begin{tabular}{|c|c|c|c|c|c|c|c|}
\hline \multirow[t]{2}{*}{ City } & \multirow[t]{2}{*}{ All ages population* } & \multirow[t]{2}{*}{ Percentage $(\%)$ of $65+y r$ olds $*$} & \multicolumn{2}{|c|}{ Daily deaths, $65+\mathrm{yr}$ olds ${ }^{\circ}$} & \multicolumn{2}{|c|}{ 25th pct of MAT $\left({ }^{\circ} \mathrm{C}\right)$} & \multirow[t]{2}{*}{ LAG } \\
\hline & & & Mean & SD & 1998-2002 & 2006-2010 & \\
\hline Trieste & 210882 & 26.0 & 6.7 & 2.7 & 23.8 & 24.3 & 6 \\
\hline Brescia & 187188 & 21.4 & 4.2 & 2.2 & 23.8 & 24.6 & 3 \\
\hline Milan & 1253503 & 22.9 & 21.6 & 6.1 & 26.2 & 24.4 & 3 \\
\hline Verona & 253267 & 21.2 & 5.2 & 2.5 & 24.9 & 24.9 & 4 \\
\hline Venezia & 270963 & 23.8 & 6.3 & 2.6 & 23.8 & 24.1 & 4 \\
\hline Turin & 864671 & 22.5 & 15.5 & 5.4 & 22.2 & 22.4 & 4 \\
\hline Bologna & 370363 & 26.6 & 9.1 & 3.3 & 25.1 & 24.7 & 3 \\
\hline Genova & 609399 & 25.7 & 17.0 & 4.4 & 25.6 & 24.7 & 3 \\
\hline Florence & 355315 & 25.7 & 8.8 & 3.2 & 26.1 & 25.2 & 3 \\
\hline Viterbo & 59263 & 19.9 & 1.1 & 1.0 & 24.4 & 24.5 & 4 \\
\hline Civitavecchia & 49966 & 17.4 & 0.7 & 0.9 & 26.4 & 28.6 & 2 \\
\hline Rome & 2545860 & 19.0 & 45.1 & 9.5 & 26.0 & 26.4 & 3 \\
\hline Campobasso & 50826 & 17.6 & 0.7 & 0.9 & 19.6 & 20.0 & 2 \\
\hline Latina & 108195 & 14.1 & 1.4 & 1.2 & 26.9 & 27.2 & 1 \\
\hline Bari & 316278 & 17.2 & 5.3 & 2.4 & 25.6 & 25.3 & 3 \\
\hline Palermo & 686045 & 14.7 & 11.1 & 3.9 & 26.6 & 26.8 & 3 \\
\hline
\end{tabular}

* 2002 resident population (National Institute of Statistics. www.demo.istat.it).

$\S$ City-specific lags from the distributed lag model; 1998-2002. ${ }^{\circ}$ Over 1998-2002 period.

weak increase post intervention. Six degrees above the reference value corresponds approximately to the 75 th percentile of the city-specific MAT distribution. For temperature increases above this point, a significant reduction in the effect of heat was detected after the intervention: the highest reduction was observed between $9^{\circ} \mathrm{C}$ and $12^{\circ} \mathrm{C}$ above the reference value where the percent change dropped from $37 \%$ to $13 \%$.

\section{Time varying analysis}

Figure 4 shows the overall pre-post time-varying estimates. Two different patterns can be recognized in the two periods studied. Before the intervention, a bimodal trend can be observed, with one peak in June and the other in August. Conversely, after the intervention a more homogeneous effect throughout the season was observed; the two peaks are greatly reduced while in May and September greater effects on mortality were observed.

\section{Sensitivity Analysis}

The sensitivity analysis confirmed the main analysis.

\section{Discussion}

This is the first multicenter study investigating temporal variations of the heat/mortality relationship preceding and following the introduction of a national prevention plan of the effects of heat on health.
The main finding of our study was a significant decrease in the effect of high temperatures on mortality in the elderly $(65+$ years old) in the period following the implementation of the Italian national prevention plan, although some degree of heterogeneity between cities was observed. The decrease was observed only in correspondence with high temperatures, approximately above the $75^{\text {th }}$ percentile of city-specific temperature summer distribution, while no variations or increases in the effect on mortality were observed with lower temperatures.

Time-varying analysis results showed a reduction in the effect of temperatures in August and an increase in the months of May, June and September between the two periods. These changes over time may be explained by differences in the level of exposure, and changes in population susceptibility and adaptive capacity [2].

It should be considered that the introduction of cityspecific HHWWS and prevention activities within the Italian heat Prevention Plan since 2004 might have improved the adaptive capacity of the population between the two study periods.

The national program is mainly focused on preventing the effects of extreme temperatures, in particular during heat waves, when level 2 and 3 warnings are issued and most prevention measures are activated, and media attention is high. However, when level 1 pre-warnings are issued, corresponding with milder temperatures, not all prevention activities are activated. Extreme temperatures are more frequent in the central months of the 


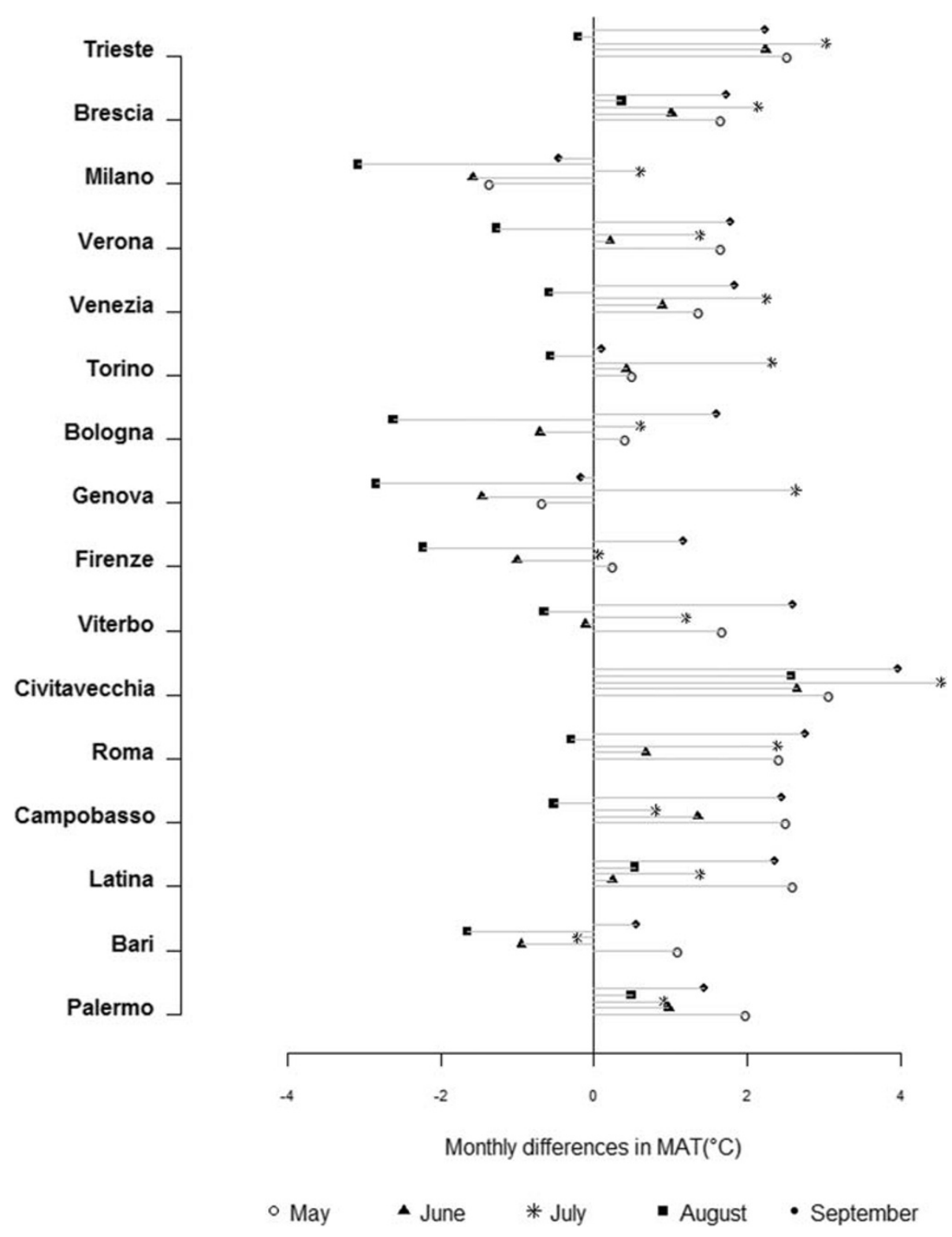

Figure 1 City-specific monthly difference in 75th percentile values of MAT pre (1998-2002) and post (2006-2010) intervention.

summer season, July and August, whereas level 1 prewarnings are mainly issued at the beginning and the end of the summer. Furthermore it has to be considered that although HHWWS is operational in May and the public is alerted through the media, most prevention measures specifically targeted to susceptible subgroups are activated in June when the first hot episodes may have already occurred. This combination of factors might justify the different temporal trends observed in correspondence with mild and high temperatures.

Two other Italian studies have attempted to analyse temporal variations in the heat-mortality relationship $[7,10]$, suggesting a decrease in the impact of high temperature on mortality in the years following 2003; however, in both cases the short study period might have affected the validity of the results. Similarly, at the international level, some studies have documented decreasing effects of heat on mortality that have been explained by an improvement in individual and infrastructure adaptation as a consequence of the introduction of HHWWS and prevention programs, an increase in population awareness, and the widespread use of home air conditioning [3-6,8,9,25,26].

The two other important factors that may contribute to the observed difference in the two periods are variations in the seasonality of the exposure and changes over time in the pool of susceptible subjects. 


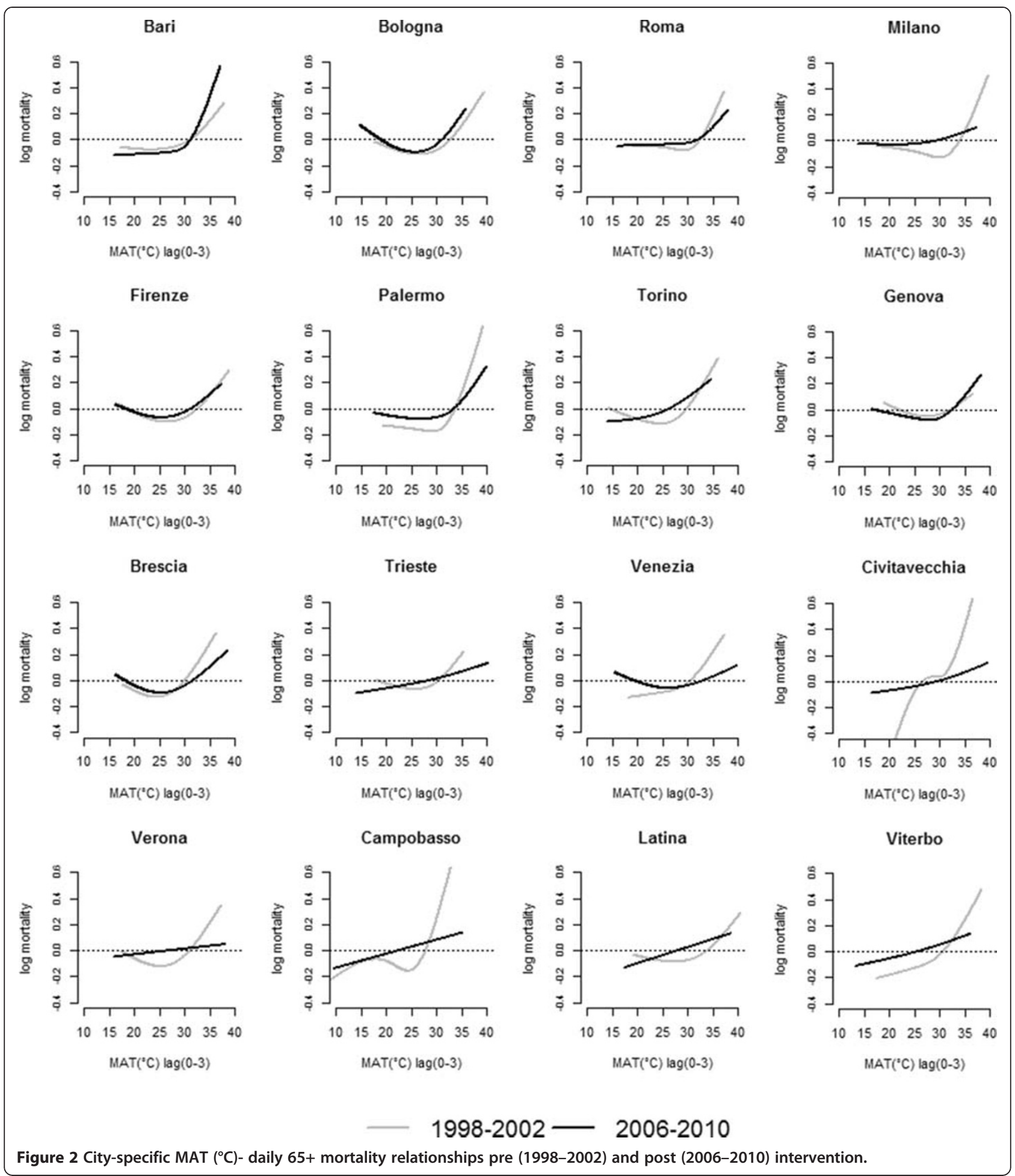

Although the period analysed is relatively short, results suggest that the temperature distribution has changed showing an increase in monthly temperatures in May, July and September since the activation of the program; this is coherent with national studies on climate change, which have suggested an increase in temperatures in Italy with an elongation of the summer season $[27,28]$. These variations might explain the increase in the effect of milder temperatures values which occur when a population is less prepared to cope with these conditions.

Concerning the second aspect, in more recent years an increase in the size of the susceptible population might 


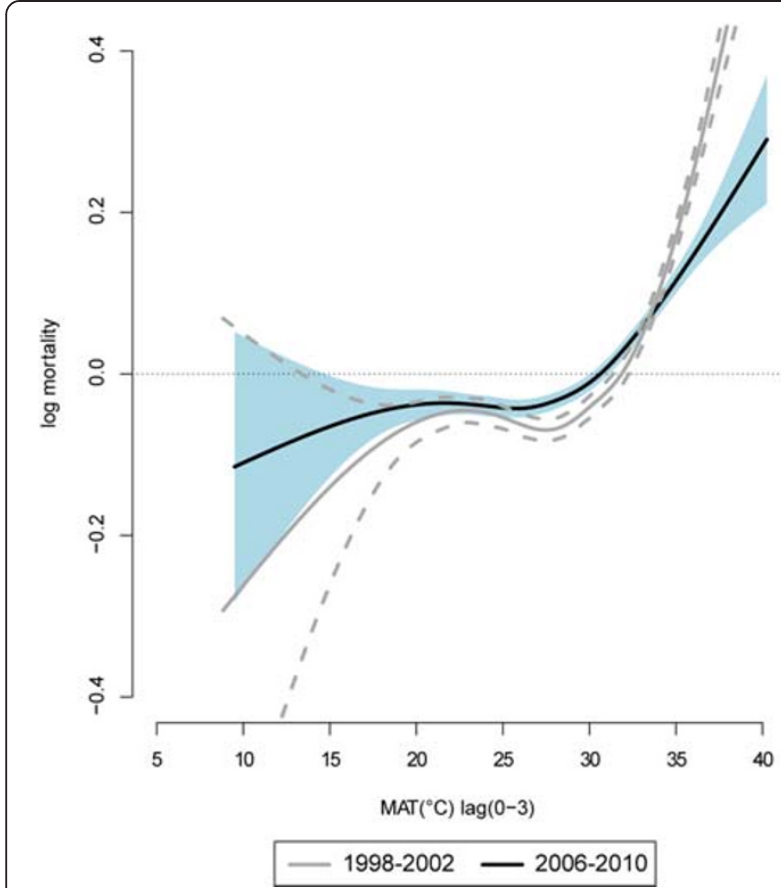

Figure 3 Overall MAT $\left({ }^{\circ} \mathrm{C}\right)$-daily $65+$ mortality relationship pre (1998-2002) and post (2006-2010) intervention.

have occurred as a consequence of the progressive aging of the population in the 16 cities. In Italy the percentage of persons over 65 increased from 18.0\% in 1999 to $20.2 \%$ in 2009 [29]. This increase might explain the increment in the effect of high temperatures early in the summer period when the size of the susceptible population is greater.

One important point of strength of our analysis is the multicenter study design, and the associated statistical power of a large study. Although the 16 cities included in our study cover a wide range of climatic and sociodemographic conditions and the effect of heat is heterogeneous, we found a similar pattern of the heatmortality relationship in most cities before and after the introduction of the program. Furthermore, the

Table 2 Overall effect of maximum apparent temperature (MAT) on daily 65+ mortality pre (1998-2002) and post (2006-2010) intervention

\begin{tabular}{lccccc}
\hline & \multicolumn{2}{c}{$\mathbf{1 9 9 8 - 2 0 0 2}$} & & \multicolumn{2}{c}{$\mathbf{2 0 0 6 - 2 0 1 0}$} \\
\cline { 2 - 3 } \cline { 5 - 6 } MAT Increase & \% change & $\mathbf{9 5 \% ~ C l}$ & & \% change & $\mathbf{9 5 \% ~ C l}$ \\
\hline 0 to 3 & 5.65 & $-3.82-16.07$ & & 5.65 & $0.60-10.96$ \\
3 to 6 & 6.72 & $-2.57-16.77$ & & 7.79 & $-0.60-16.88$ \\
6 to 9 & 24.73 & $14.22-36.21$ & & 15.60 & $10.08-21.41$ \\
9 to 12 & 36.75 & $25.73-48.88$ & & 13.31 & $6.50-20.56$ \\
12 to 15 & 41.76 & $21.41-65.53$ & & 5.65 & $-5.54-18.06$ \\
\hline
\end{tabular}

* Percent change for $3^{\circ} \mathrm{C}$ increases in MAT over the 25th city-specific percentile.

${ }^{\wedge}$ Random effect meta-analysis pooled estimates. heterogeneity test was not significant in correspondence with the highest temperature values strengthening pooled/meta-analytic estimates. Sensitivity analyses performed to test the robustness of the pooled estimates gave largely unchanged results.

The use of DLNM ensured that temporal changes in the effect of temperature on mortality simultaneously accounts for the non-linearity of the studied relationship and the delayed effect of exposure [20]. This approach overcomes some of the main critical methodological aspects typical of the study of the heat/mortality relationship [21].

More frequently the temperature effect is modelled using a linear-threshold model where the threshold is derived from segmented regression. This method has been criticized, however, because it is sensitive to the selected threshold values [21]. Moreover, the use of a linear-threshold model signifies that the effect of heat on mortality is assumed constant for the whole temperature range above the threshold, simplifying the actual relationship, and the effect on mortality of temperatures below the threshold was not analysed. Temporal variations in air pollutant concentrations may have played a different role in explaining observed temporal trends of the temperature/mortality relationship in the two periods. However, in Italy air pollution levels have decreased in recent years thanks to EU air quality Directives [30], a reduction in the number of older and polluting cars, as well as a decline in daily use of transportation by car in response to the economic crisis. The reduction in the effects of air pollution is now evident in many countries [31,32]. This aspect was not addressed in this study. Airport station temperatures were used because they were the only standardised data source available at the national level. However, although there might be a possible misclassification in exposure due to the distance from the city centre, it should be constant throughout the time period considered, thus not limiting the comparability of the estimates in the two periods.

The time-varying analysis assumes linearity even if we know that the temperature-mortality relationship is different in the different ranges of temperature. While not ideal, it helps in forming a picture of the effect's changes over the season in the two analysed periods. From this perspective, we think its application was useful.

Although the design used does not directly evaluate the effectiveness of heat prevention plan measures, pre-post analyses are widely used in other settings with similar limits for RCTs like in assessing policies to reduce air pollution [33], screening programs and routine immunization programs $[34,35]$. Every year at the national and local level considerable financial resources are devoted to heatprevention plans' implementation; however, as already mentioned, a formal evaluation has not yet been conducted and will be a challenging task. In this context, our study 

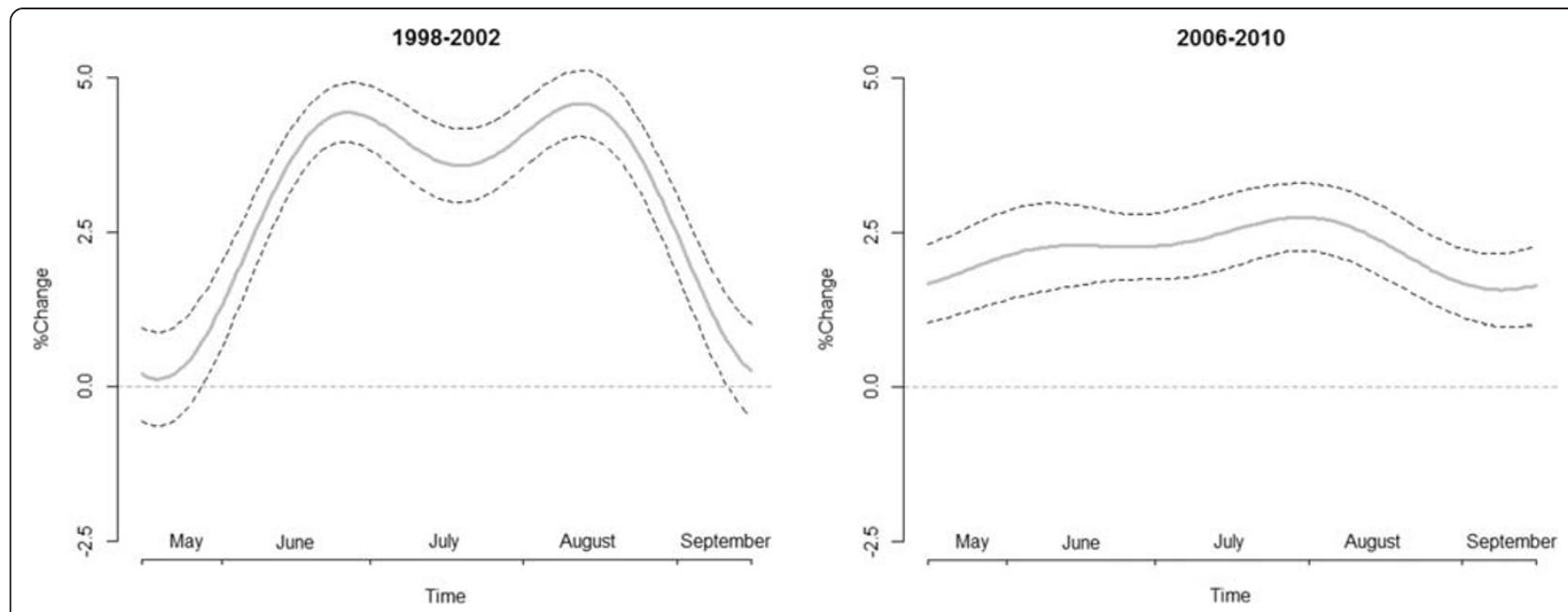

Figure 4 Overall meta-analytic time-varying effects (95\% Cl) of MAT on daily 65+ mortality (LAG 0-3) pre (1998-2002) and post (20062010) intervention.

should be considered an indirect evaluation of the effectiveness of the Italian national heat prevention plan.

\section{Conclusions}

In conclusion, our study provides evidence of a reduction in the effect of extreme summer temperatures on daily mortality in the $65+$ year old population, attributable to variations in temperature distributions during summer, variations in the pattern of population susceptibility factors, and to the introduction of adaptation measures. In the study cities prevention programmes may have played a major role in mitigating the impact of high temperatures. However, an effect of mild temperature remains, indicating a relevant impact of temperature at the beginning and the end of the summer season. In order to further reduce the burden of deaths associated with heat, prevention plans should take into account variations in the heat-mortality relationship, and probably cover a wider period of program operations to include earlier and late summer periods when the effect of heat is becoming stronger.

\section{Additional file}

Additional file 1: Table 1. City-specific percent change increase in daily $65+$ yr mortality associated with $3^{\circ} \mathrm{C}$ increases in maximum apparent temperature (MAT) pre (1998-2002) and post intervention (2006-2010). Figure 1. Plots of city-specific effects (RR, $95 \% \mathrm{Cl})$ on daily $65+$ mortality associated with $3^{\circ} \mathrm{C}$ increases in MAT pre (1998-2002) and post (2006-2010) intervention.

\section{Abbreviations}

MAT: maximum apparent temperature; RCT: Randomized Clinical Trials; HHWWS: Heat Health Watch Warning Systems; GPs: General Pratictioners; DLNM: Non-Linear Distributed Lag Model; GAM: Generalized Additive Model.
Competing interests

The author declare that they no competing interests.

\section{Authors' contributions}

PS conceived, coordinated and designed the study, it and drafted the manuscript. ML designed the study and performed the statistical analysis and contributed to the draft of the manuscript. MDS helped draft the manuscript. FdD as expert on meteorological data contributed to the discussion of results and draft of the manuscript. AMB contributed to the discussion of results and helped draft the manuscript. DD and CM helped draft the manuscript. PM helped conceive the study and helped to draft the manuscript. All authors read and approved the final manuscript.

\section{Funding}

The study has been carried out within the national Italian Heat Prevention Program funded by the Civil Protection Department, www.protezionecivile. gov.it/jcms/it/view_dossier.wp?prevPage=dossier\&contentld=DOS24694 ( accessed March 23, 2012) and the National Centre for Disease Prevention and Control of the Ministry of Health, www.ccm-network.it/ prg_area3_piano_nazionale_caldo_2009-2011 (accessed March 23, 2012).

\section{Acknowledgements}

We acknowledge Margaret Becker for her editorial help.

Received: 23 April 2012 Accepted: 16 August 2012

Published: 3 September 2012

\section{References}

1. WHO Regional Office for Europe: Fifth Ministerial Conference on Environment and Health. Italy: Parma; 2010:10-12. www.euro.who.int/en/who-we-are/ policy-documents/parma-declaration-on-environment-and-health (accessed March 23, 2012)

2. IPCC, 2007: Summary for Policymakers. In Climate Change 2007: Impacts, Adaptation and Vulnerability. Contribution of Working Group II to the Fourth Assessment Report of the Intergovernmental Panel on Climate Change. Edited by Parry ML, Canziani OF, Palutikof JP, van der Linden PJ, Hanson CE. Cambridge, UK: Cambridge University Press; 2007:7-22.

3. Davis RE, Knappenberger PC, Novicoff WM, Michaels PJ: Decadal changes in summer mortality in U.S. cities. Int J Biometeorol 2003, 47:166-175.

4. Carson C, Hajat $S$, Armstrong B, Wilkinson P: Declining vulnerability to temperature-related mortality in London over the 20th century. Am J Epidemiol 2006, 164:77-84.

5. Barnett AG: Temperature and cardiovascular deaths in the US elderly: changes over time. Epidemiology 2007, 18:369-372.

6. Sheridan SC, Kalkstein AJ, Kalkstein LS: Trends in heat-related mortality in the United States, 1975-2004. Nat Hazards 2009, 50:145-160. 
7. Michelozzi P, De Sario M, Accetta G, de Donato F, Kirchmayer U, D'Ovidio M, Perucci CA, HHWWS Collaborative Group: Temperature and summer mortality: geographical and temporal variations in four Italian cities. J Epidemiol Community Health 2006, 60:417-423.

8. Fouillet A, Rey G, Wagner V, Laaidi K, Empereur-Bissonnet P, Tertre AL, Frayssinet $P$, Bessemoulin $P$, Laurent F, Crouy-Chanel PD, Jougla E, Hémon $D$ : Has the impact of heat waves on mortality changed in France since the European heat wave of summer 2003? A study of the 2006 heat wave. Int J Epidemiol 2008, 37:309-317.

9. Kysely J, Kriz B: Decreased impacts of the 2003 heat waves on mortality in the Czech Republic: an improved response? Int J Biometerol 2008, 52:733-745

10. Morabito M, Profili F, Crisci A, Francesconi P, Gensini GF, Orlandini S: Heatrelated mortality in the Florentine area (Italy) before and after the exceptional 2003 heat wave in Europe: an improved public health response? Int J Biometeorol 2012, 56:801-810.

11. Kovats RS, Ebi KL: Heatwaves and public health in Europe. Eur J Public Health 2006, 16:592-599.

12. Michelozzi P, de' Donato FK, Bargagli AM, D'Ippoliti D, De Sario M, Marino C, Schifano P, Cappai G, Leone M, Kirchmayer U, Ventura M, di Gennaro M, Leonardi M, Oleari F, de Martino A, Perucci CA: Surveillance of Summer Mortality and Preparedness to Reduce the Health Impact of Heat Waves in Italy. Int J Environ Res Public Health 2010, 7:2256-2273.

13. World Health Organization: Heat-health action plans. In Guidance. Edited by Matthies F, Bickler G, Marín NC, Hales S. Copenhagen, Denmark: WHO Regional Office for Europe; 2008.

14. Bassil KL, Cole DC: Effectiveness of public health interventions in reducing morbidity and mortality during heat episodes: a structured review. Int J Res Public Health 2010, 7:991-1001.

15. Marinacci C, Marino M, Ferracin E, Fubini L, Gilardi L, Gilardi L, Visentin P,

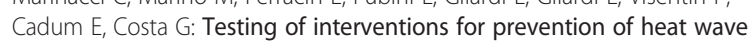
related deaths: results among frail elderly and methodological problems] [Article in Italian. Epidemiol Prev 2009, 33:96-103.

16. Conti S, Meli P, Minelli G, Solimini R, Toccaceli V, Vichi M, Beltrano C, Perini L: Epidemiologic study of mortality during the Summer 2003 heat wave in Italy. Environ Res 2005, 98:390-399.

17. Michelozzi P, de Donato F, Bisanti L, Russo A, Cadum E, DeMaria M, D'Ovidio M, Costa G, Perucci CA: The impact of the summer 2003 heat waves on mortality in four Italian cities. Euro Surveill 2005, 10:161-165.

18. Kalkstein LS, Valimont KM: An evaluation of summer discomfort in the United States using a relative climatological index. Bull Am Meteorolog Soc 1986, 67:842-848.

19. O'Neill MS, Zanobetti A, Schwartz J: Modifiers of the Temperature and Mortality Association in Seven US Cities. Am J Epidemio/ 2003, 157:1074-1082.

20. Gasparrini A, Armstrong B, Kenward MG: Distributed lag non-linear models. Stat Med 2010, 29:2224-2234.

21. Armstrong B: Models for the relationship between ambient temperature and daily mortality. Epidemiology 2006, 17:624-631.

22. van Houwelingen HC, Arends LR, Stijnen T: Advanced methods in metaanalysis: multivariate approach and meta-regression. Stat Med 2002, 21:589-624

23. Peng RD, Dominici F, Pastor-Barriuso R, Zeger SL, Samet JM: Seasonal analyses of air pollution and mortality in 100 US cities. Am J Epidemiol 2005, 161:585-594

24. Baccini M, Biggeri A, Accetta G, Kosatsky T, Katsouyanni K, Analitis A, Anderson HR, Bisanti L, D'Ippoliti D, Danova J, Forsberg B, Medina S, Paldy A, Rabczenko D, Schindler C, Michelozzi P: Heat effects on mortality in 15 European cities. Epidemiology 2008, 19:711-719.

25. Weisskopf MG, Anderson HA, Foldy S, Hanrahan LP, Blair K, Török TJ, Rumm PD: Heat Wave Morbidity and Mortality, Milwaukee, Wis, 1999 vs 1995: An Improved Response? Am J Public Health 2002, 92:830-833.

26. O'Neill MS, Zanobetti A, Schwartz J: Disparities by Race in Heat-Related Mortality in Four US Cities: The Role of Air Conditioning Prevalence. J Urban Health 2005, 82:191-197.

27. Brunetti M, Buffoni $L$, Maugeri M, Nanni T: Trends of minimum and maximum daily temperatures in Italy from 1865 to 1996 . Theor Appl Climatol 2000, 66:49-60.

28. WHO Regional Office for Europe: In Environment and health risks from climate change and variability in Italy. Edited by Wolf T, Menne B. Copenhagen, Denmark: World Health Organization; 2007.
29. Italian National Institute of Statistics (ISTAT): Annuario statistico italiano. in Italian: Annual Report on Italian Statistics; 2011. www3.istat.it/dati/catalogo/ 20111216_00/ (accessed March 23, 2012).

30. European Parliament and Council: Directive 2008/50/EC of 21 May 2008 on ambient air quality and cleaner air for Europe. http://eur-lex.europa.eu/ LexUriServ/LexUriServ.do?uri=CELEX:32008L0050:EN:NOT (accessed March 23, 2012).

31. Medina S, Plasencia A, Ballester F, Mücke HG, Schwartz J, Apheis group: Apheis: public health impact of PM10 in 19 European cities. J Epidemiol Community Health 2004, 58:831-836.

32. Laden F, Schwartz J, Speizer FE, Dockery DW: Reduction in fine particulate air pollution and mortality: Extended follow-up of the Harvard Six Cities study. Am J Respir Crit Care Med 2006, 173:667-672.

33. Hedley AJ, Wong CM, Thach TQ, Ma S, Lam TH, Anderson HR: Cardiorespiratory and all-cause mortality after restrictions on sulphur content of fuel in Hong Kong: an intervention study. Lancet 2002, 360:1646-1652.

34. Michielutte R, Shelton B, Paskett ED, Tatum CM, Velez R: Use of an interrupted time-series design to evaluate a cancer screening program. Health Educ Res 2000, 15:615-623.

35. Grijalva CG, Nuorti JP, Arbogast PG, Martin SW, Edwards KM, Griffin MR: Decline in pneumonia admissions after routine childhood immunisation with pneumococcal conjugate vaccine in the USA: a time-series analysis. Lancet 2007, 369:1179-1186.

doi:10.1186/1476-069X-11-58

Cite this article as: Schifano et al:: Changes in the effects of heat on mortality among the elderly from 1998-2010: results from a multicenter time series study in Italy. Environmental Health 2012 11:58.

\section{Submit your next manuscript to BioMed Central and take full advantage of:}

- Convenient online submission

- Thorough peer review

- No space constraints or color figure charges

- Immediate publication on acceptance

- Inclusion in PubMed, CAS, Scopus and Google Scholar

- Research which is freely available for redistribution 